NIST Special Publication 800-140F

\title{
CMVP Approved Non-Invasive Attack Mitigation Test Metrics:
}

CMVP Validation Authority Updates to ISO/IEC 24759

Kim Schaffer

This publication is available free of charge from:

https://doi.org/10.6028/NIST.SP.800-140F

I NFOR M A T I O N SE C UR I T Y 


\section{NIST Special Publication 800-140F}

\section{CMVP Approved Non-Invasive Attack Mitigation Test Metrics: \\ CMVP Validation Authority Updates to ISO/IEC 24759}

Kim Schaffer

Computer Security Division

Information Technology Laboratory

This publication is available free of charge from: https://doi.org/10.6028/NIST.SP.800-140F

March 2020

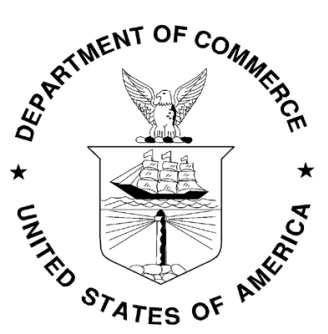

U.S. Department of Commerce Wilbur L. Ross, Jr., Secretary

National Institute of Standards and Technology Walter Copan, NIST Director and Under Secretary for Standards and Technology 


\title{
Authority
}

This publication has been developed by NIST in accordance with its statutory responsibilities under the Federal Information Security Modernization Act (FISMA) of 2014, 44 U.S.C. § 3551 et seq., Public Law (P.L.) 113-283. NIST is responsible for developing information security standards and guidelines, including minimum requirements for federal information systems, but such standards and guidelines shall not apply to national security systems without the express approval of appropriate federal officials exercising policy authority over such systems. This guideline is consistent with the requirements of the Office of Management and Budget (OMB) Circular A-130.

Nothing in this publication should be taken to contradict the standards and guidelines made mandatory and binding on federal agencies by the Secretary of Commerce under statutory authority. Nor should these guidelines be interpreted as altering or superseding the existing authorities of the Secretary of Commerce, Director of the OMB, or any other federal official. This publication may be used by nongovernmental organizations on a voluntary basis and is not subject to copyright in the United States. Attribution would, however, be appreciated by NIST.

\section{National Institute of Standards and Technology Special Publication 800-140F Natl. Inst. Stand. Technol. Spec. Publ. 800-140F, 8 pages (March 2020) CODEN: NSPUE2}

This publication is available free of charge from: https://doi.org/10.6028/NIST.SP.800-140F

Certain commercial entities, equipment, or materials may be identified in this document in order to describe an experimental procedure or concept adequately. Such identification is not intended to imply recommendation or endorsement by NIST, nor is it intended to imply that the entities, materials, or equipment are necessarily the best available for the purpose.

There may be references in this publication to other publications currently under development by NIST in accordance with its assigned statutory responsibilities. The information in this publication, including concepts and methodologies, may be used by federal agencies even before the completion of such companion publications. Thus, until each publication is completed, current requirements, guidelines, and procedures, where they exist, remain operative. For planning and transition purposes, federal agencies may wish to closely follow the development of these new publications by NIST.

Organizations are encouraged to review all draft publications during public comment periods and provide feedback to NIST. Many NIST cybersecurity publications, other than the ones noted above, are available at https://csrc.nist.gov/publications.

\section{Comments on this publication may be submitted to:}

\author{
National Institute of Standards and Technology \\ Attn: Computer Security Division, Information Technology Laboratory \\ 100 Bureau Drive (Mail Stop 8930) Gaithersburg, MD 20899-8930 \\ Email: sp800-140-comments@nist.gov
}

All comments are subject to release under the Freedom of Information Act (FOIA). 


\title{
Reports on Computer Systems Technology
}

The Information Technology Laboratory (ITL) at the National Institute of Standards and Technology (NIST) promotes the U.S. economy and public welfare by providing technical leadership for the Nation's measurement and standards infrastructure. ITL develops tests, test methods, reference data, proof of concept implementations, and technical analyses to advance the development and productive use of information technology. ITL's responsibilities include the development of management, administrative, technical, and physical standards and guidelines for the cost-effective security and privacy of other than national security-related information in federal information systems. The Special Publication 800-series reports on ITL's research, guidelines, and outreach efforts in information system security, and its collaborative activities with industry, government, and academic organizations.

\begin{abstract}
NIST Special Publication (SP) 800-140F replaces the approved non-invasive attack mitigation test metric requirements of ISO/IEC 19790 Annex F. As a validation authority, the Cryptographic Module Validation Program (CMVP) may supersede this Annex in its entirety. This document supersedes ISO/IEC 19790 Annex F and ISO/IEC 24759 paragraph 6.18.

\section{Keywords}

attack mitigation; Cryptographic Module Validation Program; CMVP; FIPS 140 testing; FIPS 140; ISO/IEC 19790; ISO/IEC 24759; non-invasive; testing requirement; vendor evidence; vendor documentation.
\end{abstract}

\section{Audience}

This document is focused toward the vendors, testing labs, and CMVP for the purpose of addressing issues in cryptographic module testing. 


\section{Table of Contents}

1 Scope

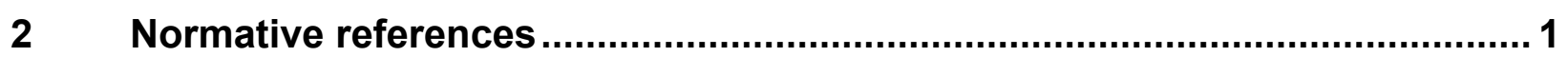

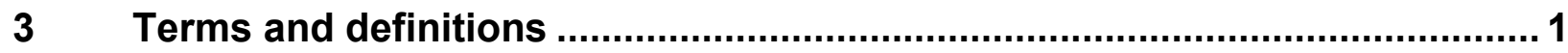

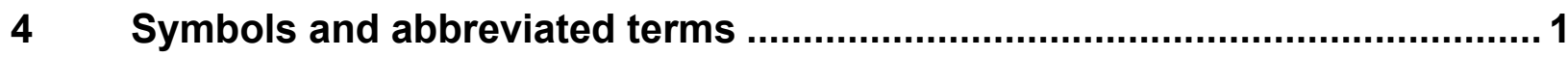

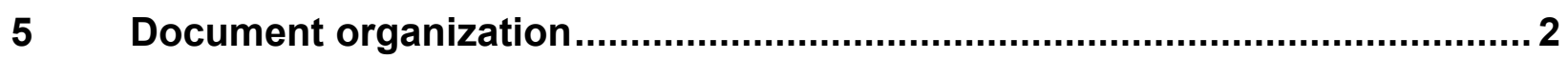

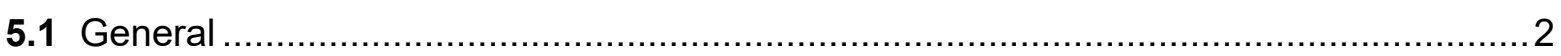

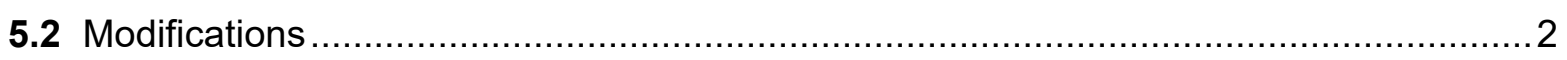

6 CMVP-approved non-invasive attack mitigation test metric requirements ... 2

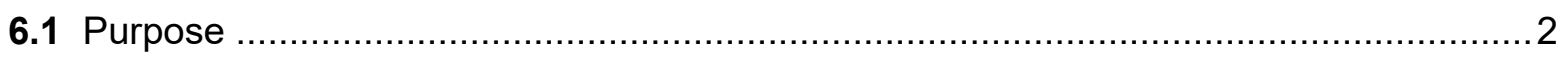

6.2 Approved non-invasive attack mitigation test metrics .............................................. 2 


\section{Scope}

This document specifies the Cryptographic Module Validation Program (CMVP) modifications of the methods to be used by a Cryptographic and Security Testing Laboratory (CSTL) to demonstrate conformance. This document also specifies the modification of methods for evidence that a vendor or testing laboratory provides to demonstrate conformity. Unless otherwise specified in this document, the test requirements are specified in ISO/IEC 24759 paragraph 6.18 .

\section{$2 \quad$ Normative references}

This section identifies the normative references cited as ISO/IEC 19790 and ISO/IEC 24759. The specific editions to be used are ISO/IEC 19790:2012 and ISO/IEC 24759:2017. Please note that the version 19790:2012 referenced here includes the corrections made in 2015.

National Institute of Standards and Technology (2019) Security Requirements for Cryptographic Modules. (U.S. Department of Commerce, Washington, DC), Federal Information Processing Standards Publication (FIPS) 140-3. https://doi.org/10.6028/NIST.FIPS.140-3

\section{$3 \quad$ Terms and definitions}

The following terms and definitions supersede or are in addition to ISO/IEC 19790 and ISO/IEC 24759.

No additional terms at this time.

\section{$4 \quad$ Symbols and abbreviated terms}

The following symbols and abbreviated terms supersede or are in addition to ISO/IEC 19790 and ISO/IEC 24759 throughout this document:

CCCS Canadian Centre for Cyber Security

CMVP Cryptographic Module Validation Program

CSD Computer Security Division

CSTL Cryptographic and Security Testing Laboratory

FIPS Federal Information Processing Standard

FISMA Federal Information Security Management/Modernization Act

NIST National Institute of Standards and Technology 
SP 800-XXX NIST Special Publication 800 series document

\section{Document organization}

\subsection{General}

Section 6 of this document replaces the approved non-invasive attack mitigation test metrics requirements of ISO/IEC 19790 Annex F and ISO/IEC 24759 paragraph 6.18.

\subsection{Modifications}

Modifications will follow a similar format as in ISO/IEC 24759. For additions to test requirements, new Test Evidence (TEs) or Vendor Evidence (VEs) will be listed by increasing the "sequence_number." Modifications can include a combination of additions using underline and deletions using strikethrough. If no changes are required, the paragraph will indicate "No change."

\section{$6 \quad$ CMVP-approved non-invasive attack mitigation test metric requirements}

\subsection{Purpose}

This document identifies CMVP-approved non-invasive attack mitigation test metrics.

\subsection{Approved non-invasive attack mitigation test metrics}

No additional requirements at this time 
NIST SP 800-140F

\section{Document Revisions}

\begin{tabular}{|l|l|}
\hline Date & Change \\
\hline & \\
\hline & \\
\hline
\end{tabular}

